\title{
Note éditoriale
}

Au-delà d'Eboli (They Did Not Stop at Eboli) est le premier volume de la série de livres Appearances rédigée en anglais américain. L'orthographe des sources matérielles et/ou historiques traduites et citées a été ajustée en fonction de cette préférence linguistique. En outre, ce premier volume est une édition bilingue françaisanglais qui est le résultat d'une collaboration fructueuse et réussie avec l'UNESCO.

La « liste des illustrations » de la partie I fait référence à l'ordre numérique des planches-contact de l'album de Seymour. Les lecteurs sont invités à consulter le fac-similé de l'album dans la partie II (p. 55-132) pour plus d'informations et de commentaires de David Seymour. Le fac-similé est suivi d'une traduction en français des légendes et des commentaires de Seymour (p. 133-142). L'article du Courrier de 1952 reproduit en facsimile dans le présent ouvrage est également disponible en ligne : https://unesdoc.unesco.org/ark:/48223/pf0000070990_fre.locale=en 
